Original article

\title{
Comparative analysis of annual rings of perennial forbs in the Loess Plateau, China
}

\author{
Songlin Shi ${ }^{\mathrm{a}, \mathrm{b}}$, Zongshan $\mathrm{Li}^{\mathrm{a}, *}$, Hao Wang ${ }^{\mathrm{a}, \mathrm{b}}$, Xing Wu ${ }^{\mathrm{a}}$, Shuai Wang ${ }^{\mathrm{a}}$, Xiaochun Wang ${ }^{\mathrm{c}}$, \\ Guohua Liu a , Bojie Fu ${ }^{\text {a }}$ \\ a State Key Laboratory of Urban and Regional Ecology, Research Center for Eco-Environmental Sciences, Chinese Academy of Sciences, Beijing 100085, China \\ b University of the Chinese Academy of Sciences, Beijing 100049, China

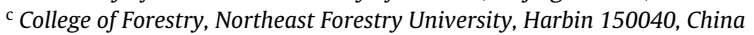

\section{A R T I C L E I N F O}

\section{Article history:}

Received 17 November 2015

Received in revised form 2 March 2016

Accepted 21 March 2016

Available online 26 March 2016

\section{Keywords:}

Herb-chronology

Anatomical patterns

Secondary root xylem

Permanent main root

Growth rate

Age distribution

\begin{abstract}
A B S T R A C T
Although recent studies have demonstrated that annual growth rings are present among perennial forbs species at high northern latitudes, little is known about whether there are demarcated growth rings of perennial forbs in the Loess Plateau of China where plant growth is strongly limited by dry climate conditions and severe soil erosion. In this study, we collected the main roots of 11 perennial forbs species along the precipitation gradient in the Loess Plateau, and analyzed the growth rings in the secondary root xylem. We found that ten species showed distinct annual growth rings, and the anatomical patterns, including vessel size and density, varied considerably among different families. Our results suggest, for forbs species in the Loess Plateau, that vessel diameter in the root xylem was strongly correlated with growth rate of the forb's roots. Ring widths of the forbs showed a significant declining trend, reflecting the deteriorating signal of growth condition with age. In comparison to other families, forb species of Fabaceae usually have the evidently larger vessels that link directly to higher hydraulic capacity and growth rate. In terms of annual ring width patterns, this study provides an applicable approach to detecting effects of limited climatic conditions and life history strategies on herbaceous vegetation in the Loess Plateau.
\end{abstract}

(c) 2016 Elsevier GmbH. All rights reserved.

\section{Introduction}

Previous studies have demonstrated that annual growth rings in the secondary xylem of permanent primary roots are widespread among many dicotyledonous perennial forbs of the temperate seasonal zones in the Northern Hemisphere (Dietz and Ullmann, 1997; Dietz and Schweingruber, 2002; von Arx and Dietz, 2006; Liu and Zhang, 2007). The phenological observations and comparative experimental studies have verified that the growth rings of the forb species are formed annually, and represented true annual growth increments (Dietz and Ullmann, 1997; Dietz and Fattorini, 2002). The patterns of growth rings in forbs may vary in different environmental conditions, and growth rings may be missing or false under the extremely adverse growth conditions (Dietz and Ullmann, 1998; Dietz and Fattorini, 2002; Moloney et al., 2009). In addition, annual rings of forbs can respond rapidly and sensitively to climatic fluctuations (Dietz and von Arx, 2005; Liu and Zhang, 2010), as well as other environmental factors, such as alti-

\footnotetext{
* Corresponding author.

E-mail address: zsli_st@rcees.ac.cn (Z. Li).
}

tudinal gradients (von Arx et al., 2006; Olano et al., 2013) and anthropogenic disturbances (Dietz and Fattorini, 2002; Dietz and Schweingruber, 2002). Consequently, growth rings of forbs can be considered as a useful approach to study growth forms and life history strategies of forbs across a wide environmental range (Moloney et al., 2009; von Arx et al., 2012; Olano et al., 2013).

As an arid and semi-arid area, the Loess Plateau of China is one of the world's most eroded regions and its dry wind-blown soil can only foster very fragile ecosystems (Yang et al., 1999; Fu et al., 2009). However, long-term agricultural exploitation has led to seriously ecological problems, such as vegetation degradation, soil desiccation and desertification (Wang et al., 2010; Feng et al., 2013). In order to restore the disturbed and over-exploited ecosystems in the Loess Plateau, the Chinese government has launched the large-scale Grain-for-Green Project (GFGP) since 1999, which plays an important role in controlling soil erosion and providing ecological rehabilitation (Zhang and Shao, 2003; Yin et al., 2010). Due to this project, a great number of slope croplands have been converted into grasslands (including abandoned lands and artificial grasslands), and vegetation cover has increased sharply (Fu et al., 2011; Lu et al., 2015). Thus, the Loess Plateau should be an ideal region for large-scale examining the existence and patterns 


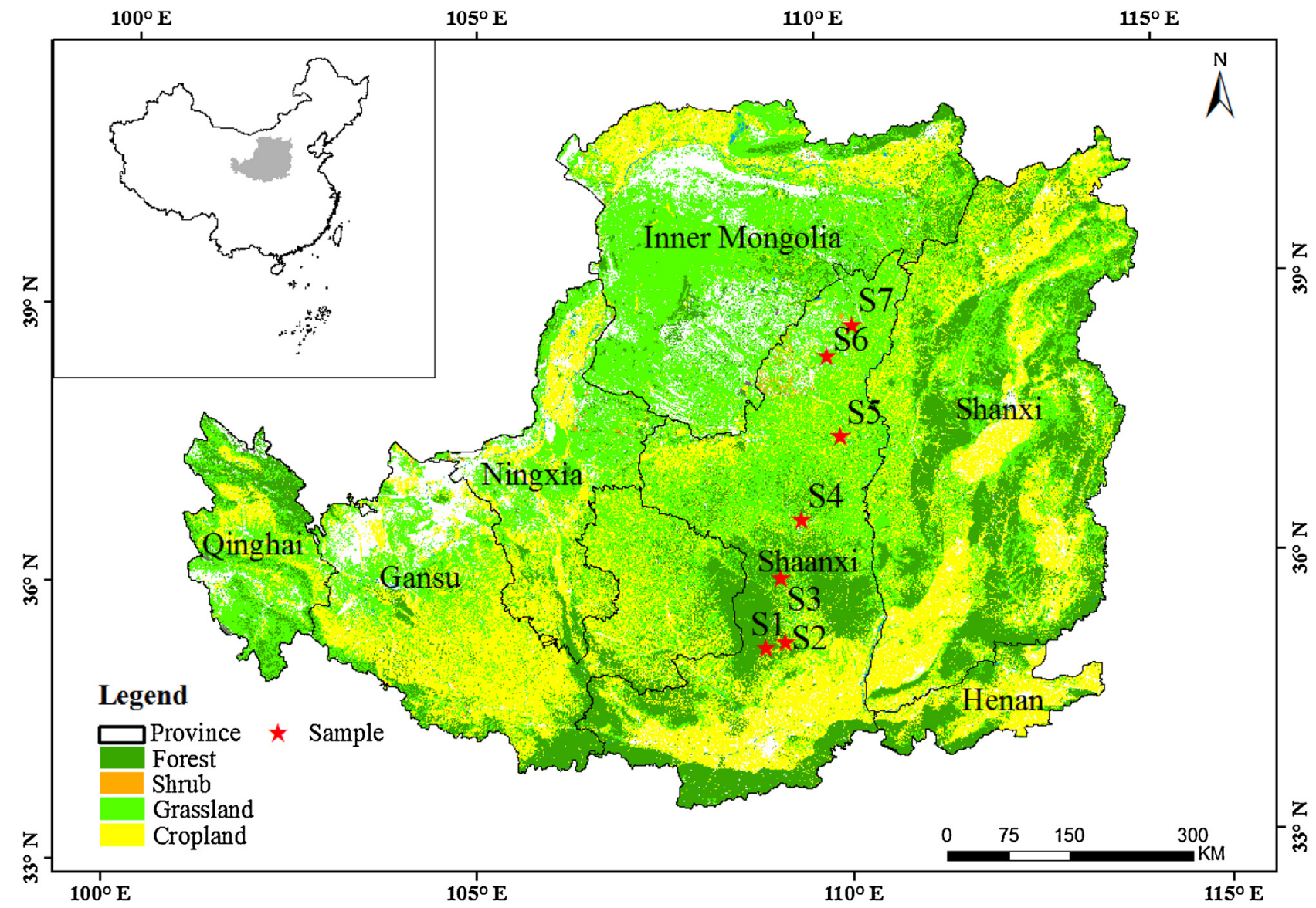

Fig. 1. Locations of 7 study sites of perennial forbs species sampled across the Loess Plateau, China.

of growth rings in roots of the perennial forbs, and exploring life history strategies and age structure of herbaceous vegetation in the stressful growing conditions.

The objectives of the present study included the following: (1) to analyze the presence and patterns of growth rings in the secondary root xylem of perennial forbs in the Loess Plateau; (2) to evaluate xylem traits of root among forbs species and whether the diameter of vessels may have the potential to constrain growth rate; and (3) to explore age structure and life history strategies of perennial forbs in the severe-erosion soil and dry climate.

\section{Materials and methods}

\subsection{Study sites}

Sampling was performed along the precipitation gradient in the central Loess Plateau, Shaanxi Province, China (Fig. 1). The transect covers longitudes from $108^{\circ} 56^{\prime} \mathrm{E}$ to $110^{\circ} 21^{\prime} \mathrm{E}$ and latitudes from $35^{\circ} 20^{\prime} \mathrm{N}$ to $38^{\circ} 47^{\prime} \mathrm{N}$ (Table 1 ). The region is dominated by a temperate, arid and semi-arid continental monsoon climate. The mean annual precipitation ranges from 397 to $587 \mathrm{~mm}$ (more than $70 \%$ of the annual precipitation occurs in the summer season), the mean annual temperature decreases from $10.6^{\circ} \mathrm{C}$ to $8.4^{\circ} \mathrm{C}$ from the south to north (according to data from Chinese meteorological station from 1952 to 2010), and elevation ranging from 1058 to $1328 \mathrm{~m}$ (Table 1).

\subsection{Field sampling}

From later April to early June 2014, we selected 7 sites along the precipitation transect (from sample site S1 to S7, the mean annual precipitation gradually reduces), and two sites were located at the transition zone from forest to grassland, four sites were located at the transition zone from shrubland to grassland, and one site was located at typical grassland (Table 1). At each sampling site, almost all perennial forbs species with obvious permanent main

Table 1

Site charateristics of perennial forbs species sampled in the Loess Plateau, China

\begin{tabular}{|c|c|c|c|c|c|c|}
\hline Sample ID & Sites & Longitude & Latitude & Altitude & Habitat & Species \\
\hline S1 & Yijun, Tongchuan & $108^{\circ} 56^{\prime}$ & $35^{\circ} 20^{\prime}$ & $1250 \mathrm{~m}$ & forest edge, roadside & PM \\
\hline S2 & Yijun, Tongchuan & $109^{\circ} 13^{\prime}$ & $35^{\circ} 24^{\prime}$ & $1175 \mathrm{~m}$ & shrub edge & SO, OB, PU \\
\hline S3 & Fuxian, Yanan & $109^{\circ} 11^{\prime}$ & $36^{\circ} 5^{\prime}$ & $1275 \mathrm{~m}$ & shrub edge, roadside & OR, PM, OB, PC, P' \\
\hline S4 & Yangjuangou, Yanan & $109^{\circ} 31^{\prime}$ & $36^{\circ} 42^{\prime}$ & $1201 \mathrm{~m}$ & shrub edge & PC, OR \\
\hline S5 & Suide, Yulin & $110^{\circ} 6^{\prime}$ & $37^{\circ} 35^{\prime}$ & $1058 \mathrm{~m}$ & grassland & MS \\
\hline S6 & Yuyan, Yulin & $109^{\circ} 58^{\prime}$ & $38^{\circ} 27^{\prime}$ & $1328 \mathrm{~m}$ & forest edge & $\mathrm{MS}, \mathrm{AF}, \mathrm{PC}$ \\
\hline S7 & Shenmu, Yulin & $110^{\circ} 21^{\prime}$ & $38^{\circ} 47^{\prime}$ & $1240 \mathrm{~m}$ & shrub edge & MS, PS, AM \\
\hline
\end{tabular}

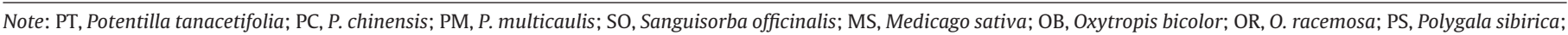
PU, Pulsatilla chinensis; AF, Artemisia frigida; AM, Astragalus melilotoides. 
roots that allow analysis of annual ring were selected, but the species with fibrous root systems, such as all the Garmineae species and some kind of dicotyledonous herbs, were not suitable for herbchronology and were excluded in this study. Additionally, all kinds of annual herbs, which have no structure of annual rings, are also excluded from the analysis in this study. Totally, the root samples of 11 perennial forbs species in the Loess Plateau were collected (Table 1). At least 10 individuals per species were arbitrarily chosen and the main roots were carefully cut approximately $10 \mathrm{~cm}$ depth from the soil surface. Additionally, root diameters were measured with a steel tap. The samples were kept frozen in a refrigerator for preservation before cross section sliding.

\subsection{Laboratory procedures}

In the laboratory, approximately $10-15$ um thick cross-sections were cut from main roots (root collar) using a sledge microtome, and then were stained with safranin and fast green solution in order to distinguish between lignified (red) and non-lignified (green) xylem cell structure (Schweingruber and Poschlod, 2005; Liu and Zhang, 2007).

The cell walls of vessels and lignified parenchyma cells in the root cross sections were observed under a dissecting microscope (OLYMPUS CX 41), which were photographed by using a digital camera (OLYMPUS, DP26-CU, resolution $2448 \times 1920$ pixels). Clear images of these sections were obtained for the next processing and analysis. Multiple overlapping images were taken from each sample and stitched together using PTGui (New House Internet Services B.V., Rotterdam, The Netherlands), in order to obtain highresolution images of entire cross-sections (von Arx et al., 2012). The presence and patterns of growth rings in the main roots were analysed by recognizing earlywood (large vessels) and latewood (small vessels) in the secondary xylem (Dietz and Ullmann, 1997) (Fig. 2). The determination of plant age was based on the observation of the number of growth rings in the digital images. Three separate rays were analyzed for each individual to account for tangential variation in growth ring width, and the means of the three measurements were used for further analysis (Dietz and von Arx, 2005). In rare cases, there might be different counts obtained from the same individual, the mean of minimum and maximum age was taken (rounded up if the mean was not an integer) and used as an estimate of true plant age (Dietz and von Arx, 2005; von Arx et al., 2006).

The large vessel diameter of nine species that showed distinct growth rings were measured manually using the cellSens Standard software (OLYMPUS). Ring widths of four species (Medicago sativa, Potentilla tanacetifolia, Sanguisorba officinalis and Potentilla chinensis) were measured manually using image processing program (Image Tool for Windows Version 3.00, UTHSCSA), because these four species had a relative long life span. The mean of the three radii measurements was calculated for each individual, used as the width of the respective growth rings (Dietz and Fattorini, 2002). In addition, the mean root growth rates ( $\mathrm{G} ; \mathrm{mm}$ year ${ }^{-1}$ ) of forb species were calculated as root diameter by root diameter $(\mathrm{R}$; $\mathrm{mm}$ ), divided by the estimated plant age (A; years): $G=R / A$.

\subsection{Statistical analysis}

The measured growth ring widths of each individual were standardized using the following equation:

$\mathrm{W}=\frac{x-\bar{x}}{s}$

where $\mathrm{W}$ denotes the standardized ring widths, $x$ is the measured ring widths, $\bar{x}$ and $s$ represent the mean and standard deviation of the measured ring widths for each individual, respectively (Liu and
Zhang, 2007). The process of standardization is necessary because it can bring all values to compatible units from a distribution with a mean of zero and a standard deviation of one (Dietz and von Arx, 2005).

Pearson correlation tests were used to quantify the relationships between vessel diameter and the mean root growth rates across species. For four species, M. sativa, P. tanacetifolia, S. officinalis and $P$. chinensis, the standardized growth ring widths for all individuals were calculated. We then examined how standardized annual ring widths were related to years using general linear models (GLMs). Later, we test the significance of the explanatory terms with commonly used F-test. The names of plant species were described based on the Chinese Flora. All analyses were conducted with R 2.10 (R Development Core Team).

\section{Results}

\subsection{Presence of growth rings in the root secondary xylem}

Growth rings in the root anatomical patterns of the sampled forb species were observed according to significant differences in vessel diameter and density of vessels between earlywood and latewood, which demonstrated smaller vessels and lower density of vessels in the latewood than in the earlywood (Fig. 2A-J). Among the 11 forb species investigated, nine species showed distinct growth rings in the root sections, and Artemisia frigida (Asteraceae) had roughly recognizable growth rings. Specifically, the Fabaceae species showed a very distinct ring structure. Pulsatilla chinensis (Ranunculaceae) indicated diffuse root anatomical patterns over the entire radius and no distinguishable growth rings (Table 2, Fig. 2).

\subsection{Anatomical patterns among species}

The anatomical patterns of the forb species were different considerably among the different families (Table 2, Fig. 2). For example, $M$. sativa (Fabaceae) indicated clearly visible growth rings featured by semi-ring porous wood (Fig. 2J), while P. chinensis (Ranunculaceae) showed indistinct growth rings boundaries with differential vessel density (Fig. 2K). Additionally, similar anatomical patterns were manifested within the same family. (Table 2, Fig. 2). For instance, all Fabaceae demonstrated zonal branching of vessel rays (Fig. 2B, C, E, J), whereas all Rosaceae indicated differential vessel density (Fig. 2A, F-H).

From the comparison of vessel diameter among different species sampled (Fig. 3), most forb species of Fabaceae have the evidently larger vessels than those species of other families, such as Rosaceae and Ranunculaceae. Meanwhile, vessel diameter exhibited a significant positive relationship $(r=0.74, p<0.05)$ with growth rate, suggesting vessel diameter in the root xylem was a key trait influencing growth rate among the forb species.

\subsection{Age distribution}

The age of a large portion of the sampled individuals was relatively young, only less than five years old. However, quite a few individuals had relatively older age. For example, more than one quarter of the sampled forbs were more than ten years old and the oldest forb was 14 years old (Fig. 4).

Age distribution varied considerably among species that indicated clear annual rings (Fig. 5). Most of species were relatively young and the age was in the range from two to six years. Oxytropis racemosa (Fabaceae) was the youngest species and most of individuals were less than 4 years old, whereas $M$. sativa was the oldest species and a large proportion of individuals was more than 12 years old (Fig. 5). Correspondingly, M. sativa, Potentilla chinensis and 

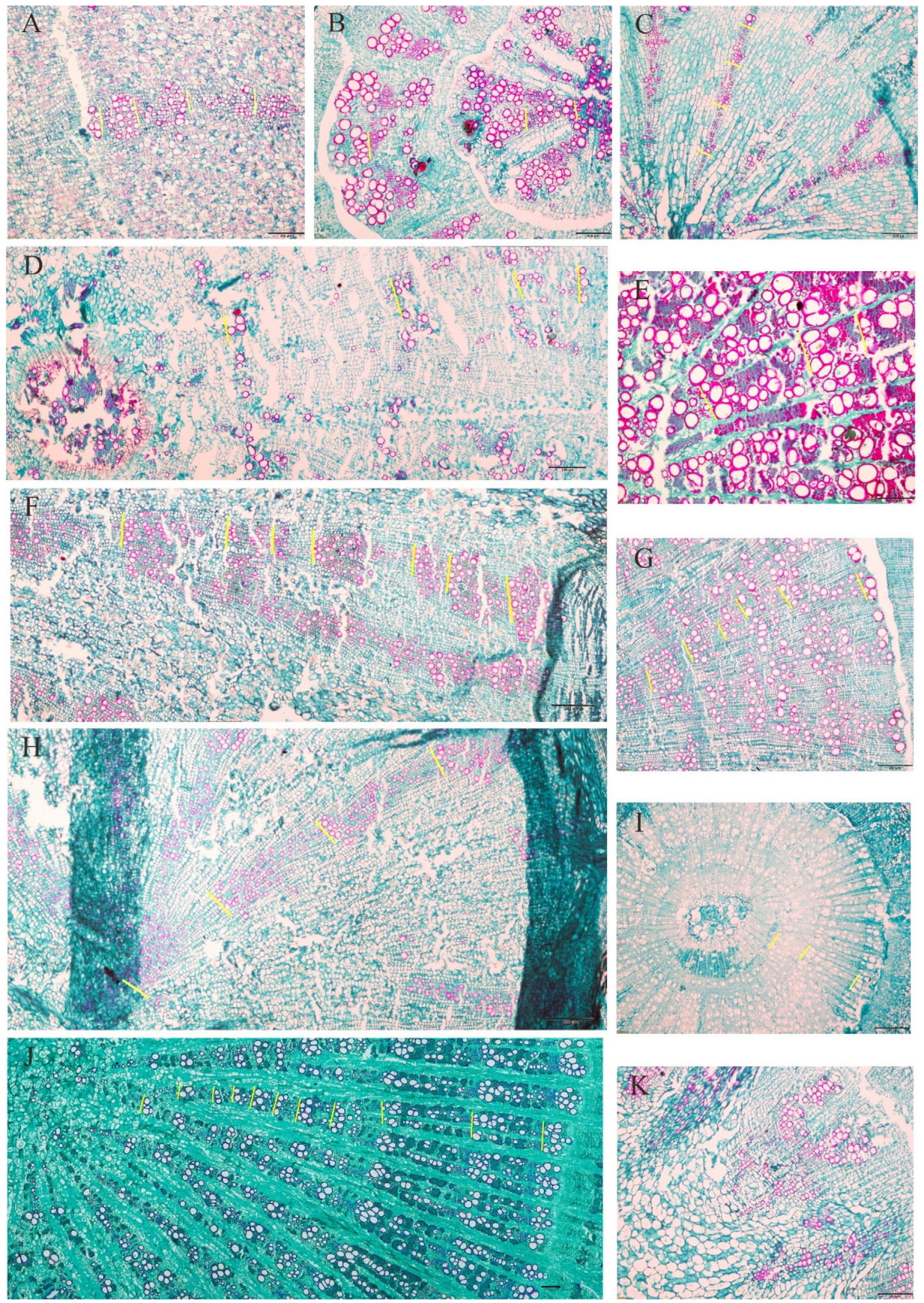

Fig. 2. Anatomical patterns of growth rings in the secondary root xylem. (A) Sanguisorba officinalis, (B) Oxytropis racemosa, (C) Oxytropis bicolor, (D) Artemisia frigida, (E) Astragalus melilotoides, (F) Potentilla tanacetifolia, (G) Potentilla chinensis, (H) Potentilla multicaulis, (I) Polygala sibirica, (J) Medicago sativa, (K) Pulsatilla chinensis. The yellow markers demarcate transitions from latewood of the previous growing period to earlywood of the following one. The horizontal black bars at the bottom of each panel manifest $200 \mu \mathrm{m}$. (For interpretation of the references to colour in this figure legend, the reader is referred to the web version of this article.) 
Table 2

Patterns in the secondary xylem of roots in 11 perennial forbs species sampled in the Loess Plateau, China.

\begin{tabular}{|c|c|c|c|c|}
\hline Family & Species & Number of samples & Ring boundary & Pattern \\
\hline \multirow[t]{4}{*}{ Rosaceae } & Potentilla tanacetifolia & 14 & Distinct & VL,VD \\
\hline & P. chinensis & 30 & Distinct & VL,VD \\
\hline & P. multicaulis & 34 & Distinct & VL,VD \\
\hline & Sanguisorba officinalis & 13 & Distinct & VL, VD \\
\hline \multirow[t]{4}{*}{ Fabaceae } & Medicago sativa & 33 & Distinct & VL, VB \\
\hline & Oxytropis bicolor & 24 & Distinct & VL, VB \\
\hline & O. racemosa & 18 & Distinct & VL, VB \\
\hline & Astragalus melilotoides & 10 & Distinct & VL, VB \\
\hline Polygalaceae & Polygala sibirica & 11 & Distinct & VL,VD \\
\hline Ranunculaceae & Pulsatilla chinensis & 11 & Questionable & VD \\
\hline Asteraceae & Artemisia frigida & 10 & Recognizable & VL, VD \\
\hline
\end{tabular}

VB, zonal branching of vessel rays; VD, differential vessel density; VL, Differential vessel lumina; (Dietz and Ullmann, 1997; Dietz and Schweingruber, 2002).

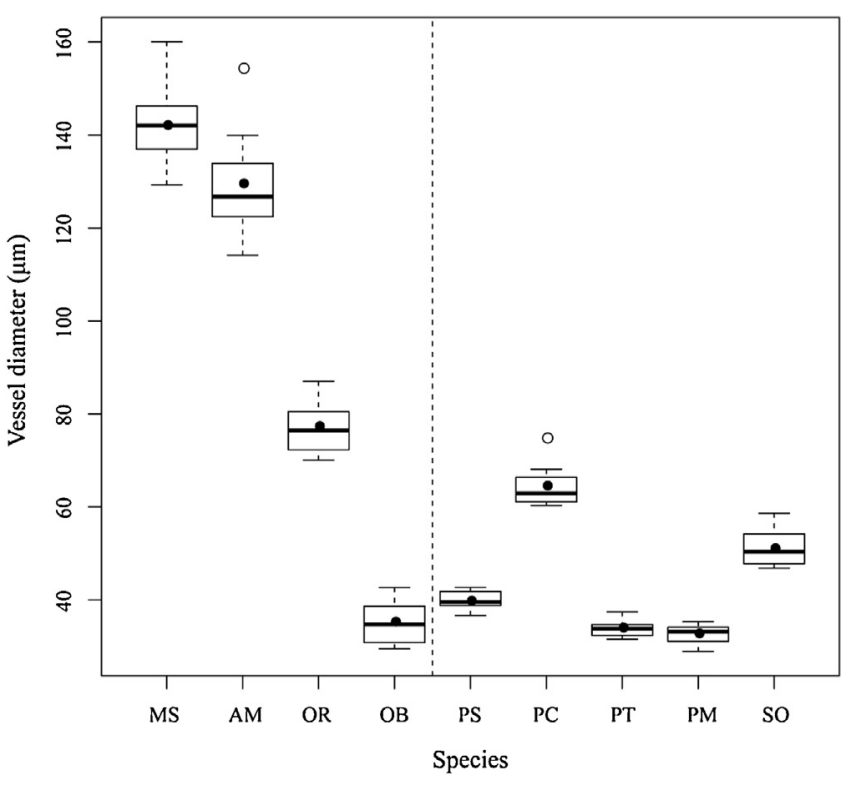

Fig. 3. The vessel size of each species indicated clear growth rings. PT, Potentilla tanacetifolia; PC, P. chinensis; PM, P. multicaulis; SO, Sanguisorba officinalis; MS, Medicago sativa; OB, Oxytropis bicolor; OR, O. racemosa; AM, Astragalus melilotoides; PS, Polygala sibirica.

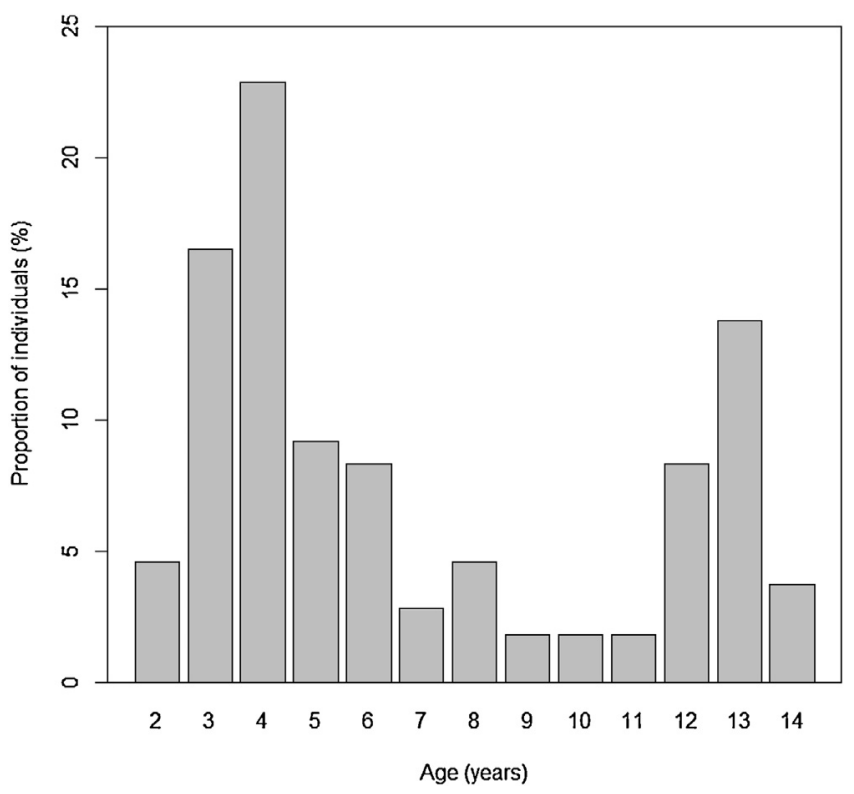

Fig. 4. Age distribution of all individuals of species indicated clear growth rings.

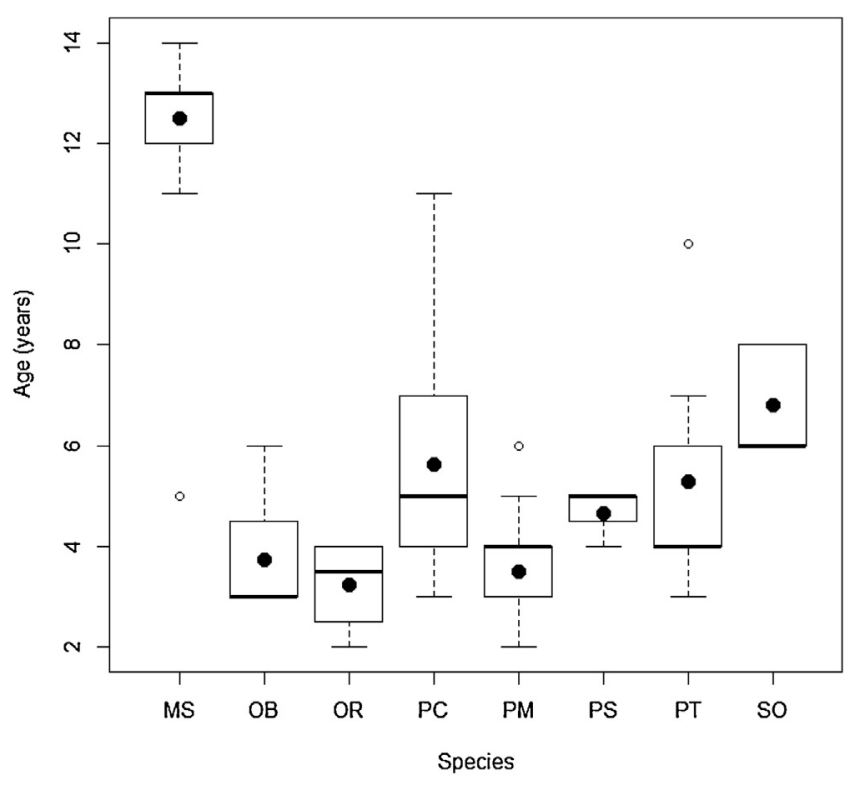

Fig. 5. Age distribution of each species indicated clear growth rings. PT, Potentilla tanacetifolia; PC, P. chinensis; PM, P. multicaulis; SO, Sanguisorba officinalis; MS, Medicago sativa; OB, Oxytropis bicolor; OR, O. racemosa; PS, Polygala sibirica.

$P$. tanacetifolia were relatively older species, the oldest individual for each species was 14,11 and 10 years old, respectively.

\subsection{Patterns of growth ring width}

The fluctuating patterns of ring widths for the older species ( $M$. sativa, Potentilla chinensis, P. tanacetifolia and S. officinalis) were roughly consistent during the period from 2003 to 2013 (Fig. 6). The annual ring widths of the three species indicated a significant decreasing trend over time, and the linear correlation analysis reached the significant level for the species of $M$. sativa $(r=-0.93$, $p<0.001$, Fig. 6d), Potentilla chinensis ( $r=-0.7, p<0.05$, Fig. $6 \mathrm{~b})$ and P. tanacetifolia ( $r=-0.96, p<0.001$, Fig. 6c). Meanwhile, S. officinalis showed a generally non-significant decrease of annual ring widths with year (Fig. 6a).

The widest ring width of Potentilla chinensis and P. tanacetifolia occurred at the time of 2005 , while $M$. sativa had the largest annual growth increment at the time of 2003. Potentilla chinensis had the narrowest growth increment in the time of 2012, whereas the narrowest ring width of M. sativa occurred at the time of 2011 (Fig. 6). 

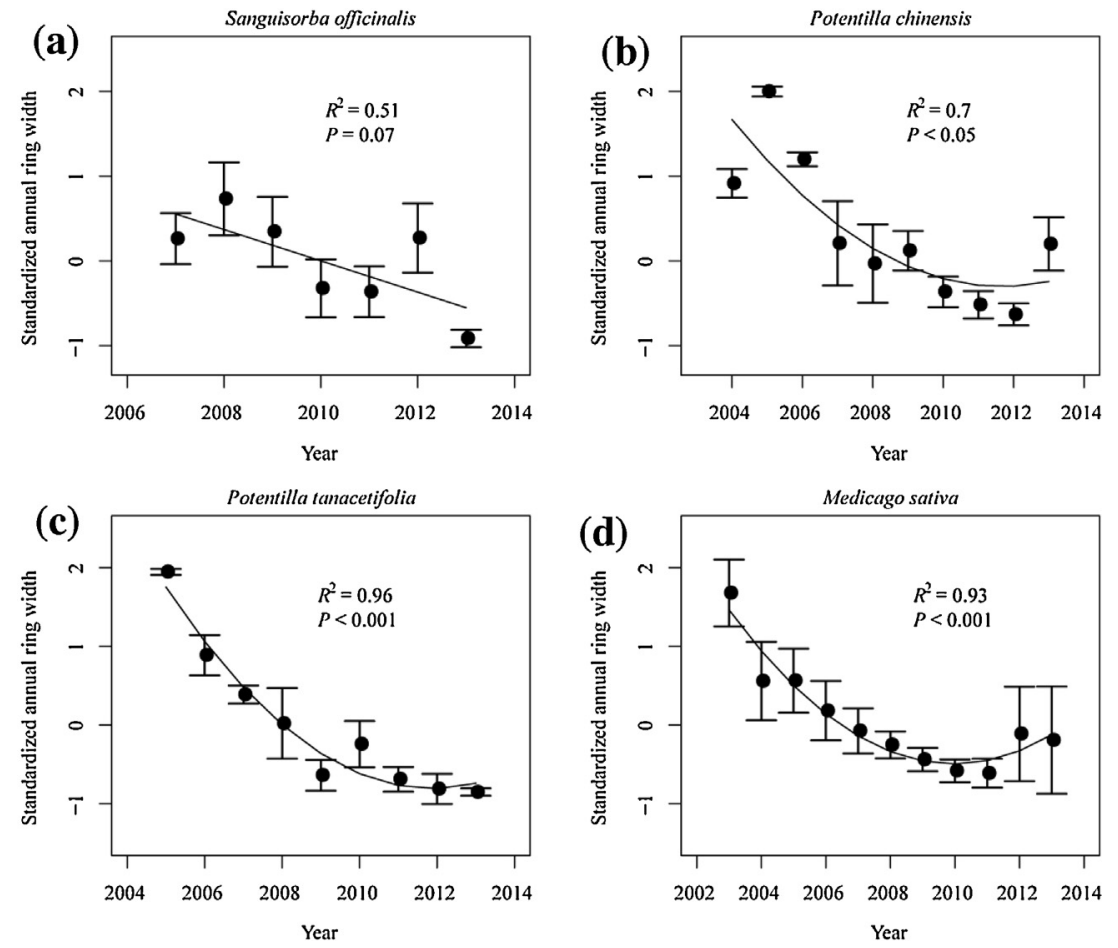

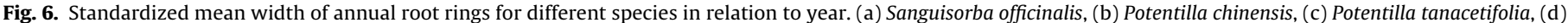
Medicago sativa.

\section{Discussion}

\subsection{Presence and patterns of annual growth rings}

This study presents the large-scale investigation for the existence of annual rings in the secondary root xylem of perennial forbs in the Loess Plateau of China. Our results show that $91 \%$ of the sampled species retaining a permanent main root demonstrated the distinguishable growth rings, and this proportion is higher than that reported in central European lowlands (66\%, Dietz and Ullmann, 1997), North America (65\%, Dietz and Schweingruber, 2002) and Inner Mongolia grassland (62\%, Liu and Zhang, 2007). The obviously higher proportion of forb species showing growth rings in the Loess Plateau might be ascribed to the stressful growth conditions for plant species, such as low resource availability due to the severe-erosion soil, and severe drought threats by the low level of total rainfall and the high evapotranspiration rate.

The results of this study disagree with the suggestion that the forb's growth rings are more distinct in the habitat with higher resource availability (Dietz and Schweingruber, 2002). In the Loess Plateau, the average annual precipitation is only about $464 \mathrm{~mm}$, but the average annual reference evapotranspiration is over $700 \mathrm{~mm}$ (Zhao et al., 2014). Additionally, the Loess Plateau suffers from probably most severe soil erosion in the world, resulting in soil nutrient deficiency and relatively low levels of the organic carbon, total nitrogen and phosphorus stocks (Liu et al., 2012, 2013). Thus, low resource availability has strong negative impact on plant growth in this region. Recent studies suggest that patterns and clarity of growth rings in forb species may vary in different climatic conditions (Dietz and Ullmann, 1997; Dietz and Schweingruber, 2002). Seasonal rainfall and temperature change may play a key role in forming distinct annual rings across perennial forbs species in this region. Consequently, seasonal climate, rather than habital conditions, might be the major factor in determining clear annual rings in the primary roots of perennial forbs in the Loess Plateau.
Previous studies have suggested that annual growth rings are widespread among perennial forbs in the regions located at rather higher latitudes (above $40^{\circ} \mathrm{N}$ ), such as the central European lowlands (Dietz and Ullmann, 1997; Dietz and Fattorini, 2002), North America (Dietz and Schweingruber, 2002; Dietz and von Arx, 2005; von Arx et al., 2006), Mediterranean (Olano et al., 2013) and Inner Mongolia grassland (Liu and Zhang, 2007). In contrast, we detected distinguishable growth rings of many perennial forbs at the Loess Plateau located at comparatively lower latitudes (from 35 to $39^{\circ} \mathrm{N}$ ), and we hypothesized those perennial forbs with annual rings might widespread in the temperate seasonal zones of the Northern Hemisphere.

\subsection{The anatomical patterns of growth rings}

Our results indicated that anatomical features between earlywood and latewood are different among most of the forbs species (Fig. 2), and this make it possible to identify the growth rings and determine the age of herbaceous individuals. Overall, the earlywood usually has wider vessels and higher-vessel frequency than the latewood, and this is in accordance with several previous studies (Dietz and Ullmann, 1997; Schweingruber and Poschlod, 2005; Liu and Zhang 2007).

Recent studies based on xylem traits of woody species have shown that the vessel diameter has a significant positive correlation with growth rate (Denne et al., 1999; Russo et al., 2010). It has been suggested that wider vessels linked directly to higher hydraulic capacity allow faster rates of transpiration and photosynthesis, and thus increase growth rate and make tree species achieve greater heights (Brodribb and Feild, 2000; Stratton et al., 2000; Russo et al., 2010; Anfodillo et al., 2013). In our data, the diameter of large vessels in the root xylem was positively associated with growth rate of roots across forbs species. These results suggest that vessel size related to the level of growth rate plays a key role in determining root diameter among the forb species. Nitrogen 
is generally considered to be one of the essential limiting nutrients in controlling plant growth in the semi-arid regions (Franche et al., 2009; Liu et al., 2013), and leguminous plants can obtain partly their nitrogen by forming a symbiotic relationship with nitrogen-fixing bacteria (Jefferies et al., 1981; Franche et al., 2009). In comparison to other forb species, most forbs species of Fabaceae have relative wide vessels (Fig. 3), which enable the leguminous plants tend to have higher growth rate and bigger root in size. Additionally, the wider vessels in the roots of leguminous plants may be beneficial to assimilate more nutrients and moisture, and then increase the growth rate.

\subsection{The possibility of presence for missing/false rings}

Previous studies have demonstrated that growth rings in the roots of perennial forbs are developed annually (Dietz and Fattorini, 2002; von Arx and Dietz, 2006) and growth ring analysis is one of key ways to determine the age of forb species (Schweingruber and Poschlod, 2005). However, plant growth is usually strongly limited by adverse habital conditions, which may result in missing or false rings (Dietz and Fattorini, 2002).

According to personal interviews with local managers, a large number of seeds of $M$. sativa were sowed for the implementation of GFGP in the Suide (S5), Yuyang (S6), and Shenmu County (S7) from 2001 to 2003 . We analyzed growth rings in the root collars of primary roots of all individuals of $M$. sativa, indicating that most of individuals aged from 12 to 14 years (Fig. 4). Interestingly, the age of $M$. sativa with annual rings analysis was exactly consistent with the sowing dates. Therefore, our results confirm that the growth rings in perennial forbs roots are formed annually in the Loess Plateau. In addition, it seems to be impossible to develop missing or false rings, although herbs of these regions were under the stressful growing conditions with severe-erosion soil and dry climate conditions. This may be related to seasonal climate, because a large proportion of rainfall often occurs in the growing season, to some extent, compensating for the lack of water resources.

\subsection{Age structure of forbs in different regions}

The age is one of the most important growing traits for the perennial herbs (Weiher et al., 1999; Schweingruber and Poschlod, 2005), and considerable attention has been devoted to the ages of the perennial forbs in the central European and North America (Dietz and Schweingruber, 2002; Schweingruber and Poschlod, 2005). In this study, we present the age structures of ten forb species with clear growth rings in the Loess Plateau and show that the average age of sampled individuals ranges from three to four years old (Fig. 3), which is comparatively older than the age of forb species in the North America where half of the perennial forbs were only about two or three years old (Dietz and Schweingruber, 2002).

The plant age is not only restricted by internal physiological factors (Nooden and Penney, 2001; Thomas, 2002), but also influenced by environmental factors, such as temperature, soil nutrients and moisture (Schweingruber and Poschlod, 2005). Under stressful growing conditions, plants are usually compelled to extend individual life spans as a result of the reduced growing rate (Sonesson and Callaghan, 1991; Molau, 1997). The growth of forbs species in the Loess Plateaus is strictly limited by the lower level of resource availability, including water resources, organic carbon and total nitrogen and phosphorus stocks (Wang et al., 2010; Liu et al., 2013). The more stressful growing conditions in the Loess Plateau might partly explain the relatively older perennial species found in this region in comparison to the North America.

\subsection{Patterns of growth ring width and life history strategy}

Several studies have suggested that the growth ring patterns of forbs tightly associated to environmental factors in the temperate seasonal zone (Dietz and Fattorini, 2002; von Arx et al., 2006). von Arx et al. (2006) found that annual ring widths of forbs in the Wallowa Mountains (northeastern Oregon, USA) declined linearly with age at low and intermediate altitudes, but increased for the first few years and then declined in later years at high altitudes. In addition, Olano et al. (2013) showed that ring width of the alpine forb, Silene ciliate, decreased with plant age at all altitudinal zones (from 1986 to $2413 \mathrm{~m}$ ) in Mediterranean high mountains. On the contrary, Liu and Zhang (2007) found that ring widths of forbs in the Mongolia grassland indicated a linear increasing trend with age.

In this study, we indicated that ring widths of the three forb species with longer ages all demonstrated a significant decreasing trend with time in the semi-arid area, irrespective of whether the species were native (Potentilla chinensis and P. tanacetifolia) or introduced (M. sativa). In early life stages, herbaceous plants in the semi-arid region, such as the Loess Plateau, usually make full use of water and nutrients in soil to attain greatest root growth. This kind of life history strategy benefits the forb species to survive in the harsher growth conditions with scarce water resources and deficient soil nutrients. Greatest root growth would allow the plants to store more starch, then enhancing a potential resistance to drought stress (McDowell et al., 2008; von Arx et al., 2012). The growing rate of forbs in the Loess Plateau decreases sharply with the age, and this reflect the deteriorating growth conditions attributed to the fast exploitation of soil water and nutrients at the early life stages (Dietz et al., 2004; von Arx et al., 2006). However, forbs usually allocate a higher proportion of their resources to above-ground growth and reproduction in later years (Obeso, 2002), and this should be the additional explanation for the relatively narrow ring width founded at the later years for forbs in this study.

\section{Conclusions}

This study provides the compelling evidence that a large portion of perennial forbs with a persistent main root at the Loess Plateau can form clearly demarcated annual rings in the secondary root xylem. Herb-chronology analysis in the Loess Plateau provides us a valuable approach to studying the population age structure and life history strategy of forbs at the region of lower levels of resource availability, and exploring the relationship between the growth pattern of forbs and environmental factors under the dry climate conditions.

\section{Acknowledgements}

This study was supported by the Major Program of the National Natural Science Foundation of China (Grant no. 41390462) and Natural Science Foundation of China (Grant No. 41571503). We greatly thank Yu-jia Liu and Li Shen of the Tree Ring Laboratory, Northeast Forestry University of China, for the assistance of producing root sections and ring-width measurements. We are also indebted to YiHe Lv, Xiao-Ming Feng, and Guang-yao Gao for providing insightful comments and constructive suggestions for revising an early draft of this article.

\section{Appendix A. Supplementary data}

Supplementary data associated with this article can be found, in the online version, at http://dx.doi.org/10.1016/j.dendro.2016. 03.010 . 


\section{References}

Anfodillo, T., Petit, G., Crivellaro, A., 2013. Axial conduit widening in woody species: a still neglected anatomical pattern. Iawa J. 34, 352-364.

Brodribb, T.J., Feild, T.S., 2000. Stem hydraulic supply is linked to leaf photosynthetic capacity: evidence from New Caledonian and Tasmanian rainforests. Plant Cell Environ. 23, 1381-1388.

Denne, M.P., Cahalan, C.M., Aebischer, D.P., 1999. Influence of growth rate and cambial age on density of Rauli (Nothofagus nervosa) in relation to vessel lumen areas and numbers. Holzforschung 53, 199-203.

Dietz, H., Fattorini, M., 2002. Comparative analysis of growth rings in perennial forbs grown in an alpine restoration experiment. Ann. Bot. 90, 663-668.

Dietz, H., Schweingruber, F.H., 2002. Annual rings in native and introduced forbs of lower Michigan, USA. Can. J. Bot. 80, 642-649.

Dietz, H., Ullmann, I., 1997. Age-determination of dicotyledonous herbaceous perennials by means of annual rings: exception or rule? Ann. Bot. 80, 377-379.

Dietz, H., Ullmann, A., 1998. Ecological application of 'Herbchronology': comparative stand age structure analyses of the invasive plant Bunias orientalis L. Ann. Bot. 82, 471-480.

Dietz, H., von Arx, G., 2005. Climatic fluctuation causes large-scale synchronous variation in radial root increments of perennial forbs. Ecology 86, 327-333.

Dietz, H., von Arx, G., Dietz, S., 2004. Growth increment patterns in the roots of two alpine forbs growing in the center and at the periphery of a snowbank. Arct. Antarct. Alp. Res. 36, 591-597.

Feng, X.M., Fu, B.J., Lu, N., Zeng, Y., Wu, B.F., 2013. How ecological restoration alters ecosystem services: an analysis of carbon sequestration in China's Loess Plateau. Sci. Rep. 3, http://dx.doi.org/10.1038/srep02846.

Franche, C., Lindstrom, K., Elmerich, C., 2009. Nitrogen-fixing bacteria associated with leguminous and non-leguminous plants. Plant Soil 321, 35-59.

Fu, B.J., Wang, Y.F., Lu, Y.H., He, C.S., Chen, L.D., Song, C.J., 2009. The effects of land-use combinations on soil erosion: a case study in the Loess Plateau of China. Prog. Phys. Geogr. 33, 793-804.

Fu, B.J., Liu, Y., Lu, Y.H., He, C.S., Zeng, Y., Wu, B.F., 2011. Assessing the soil erosion control service of ecosystems change in the Loess Plateau of China. Ecol. Complex. 8, 284-293.

Jefferies, R.A., Bradshaw, A.D., Putwain, P.D., 1981. Growth, nitrogen accumulation and nitrogen transfer by legume species established on mine spoils. J. Appl. Ecol. 18, 945-956.

Liu, Y.B., Zhang, Q.B., 2007. Growth rings of roots in perennial forbs in Duolun Grassland, Inner Mongolia, China. J. Integr. Plant Biol. 49, 144-149.

Liu, Y.B., Zhang, Q.B., 2010. Effect of climate on the growth of annual rings in the main roots of perennial forbs in an Inner Mongolian semi-arid grassland, China. J. Veg. Sci. 21, 899-907.

Liu, Z.P., Shao, M.A., Wang, Y.Q., 2012. Large-scale spatial variability and distribution of soil organic carbon across the entire Loess Plateau, China. Soil Res. 50, 114-124.

Liu, Z.P., Shao, M.A., Wang, Y.Q., 2013. Spatial patterns of soil total nitrogen and soil total phosphorus across the entire Loess Plateau region of China. Geoderma 197, 67-78.

Lu, Y.H., Zhang, L.W., Feng, X.M., Zeng, Y., Fu, B.J., Yao, X.L., Li, J.R., Wu, B.F., 2015. Recent ecological transitions in China: greening, browning, and influential factors. Sci. Rep. 5, http://dx.doi.org/10.1038/srep08732.
McDowell, N., Pockman, W.T., Allen, C.D., Breshears, D.D., Cobb, N., Kolb, T., Plaut, J. Sperry, J., West, A., Williams, D.G., Yepez, E.A., 2008. Mechanisms of plant survival and mortality during drought: why do some plants survive while others succumb to drought? New Phytol. 178, 719-739.

Molau, U., 1997. Age-related growth and reproduction in Diapensia lapponica, an arctic-alpine cushion plant. Nord. J. Bot. 17, 225-234.

Moloney, K.A., Knaus, F., Dietz, H., 2009. Evidence for a shift in life-history strategy during the secondary phase of a plant invasion. Biol. Invasions 11, 625-634.

Nooden, L.D., Penney, J.P., 2001. Correlative controls of senescence and plant death in Arabidopsis thaliana (Brassicaceae). J. Exp. Bot. 52, 2151-2159.

Obeso, J.R., 2002. The costs of reproduction in plants. New Phytol. 155, 321-348.

Olano, J.M., Almeria, I., Eugenio, M., von Arx, G., 2013. Under pressure: how a Mediterranean high-mountain forb coordinates growth and hydraulic xylem anatomy in response to temperature and water constraints. Funct. Ecol. 27, 1295-1303.

Russo, S.E., Jenkins, K.L., Wiser, S.K., Uriarte, M., Duncan, R.P., Coomes, D.A., 2010. Interspecific relationships among growth: mortality and xylem traits of woody species from New Zealand. Funct. Ecol. 24, 253-262.

Schweingruber, F.H., Poschlod, P., 2005. Growth rings in herbs and shrubs: life span, age determination and stem anatomy. For. Snow Landsc. Res. 79, 199-200.

Sonesson, M., Callaghan, T.V., 1991. Strategies of survival in plants of the Fennoscandian tundra. Arctic 44, 95-105.

Stratton, L., Goldstein, G., Meinzer, F.C., 2000. Stem water storage capacity and efficiency of water transport: their functional significance in a Hawaiian dry forest. Plant Cell Environ. 23, 99-106.

Thomas, H., 2002. Ageing in plants. Mech. Ageing Dev. 123, 747-753.

Wang, Y.Q., Shao, M.A., Liu, Z.P., 2010. Large-scale spatial variability of dried soil layers and related factors across the entire Loess Plateau of China. Geoderma 159, 99-108.

Weiher, E., van der Werf, A., Thompson, K., Roderick, M., Garnier, E., Eriksson, O., 1999. Challenging theophrastus: a common core list of plant traits for functional ecology. J. Veg. Sci. 10, 609-620.

Yang, W.Z., Shao, M.A., Peng, X.D., Xia, W.S., 1999. On the relationship between environmental aridization of the Loess Plateau and soil water in loess. Sci. China Ser. D-Earth Sci. 42, 240-249.

Yin, R.S., Yin, G.P., Li, L.Y., 2010. Assessing China's ecological restoration programs: what's been done and what remains to be done? Environ. Manage. 45, $442-453$.

Zhang, X.C., Shao, M.A., 2003. Effects of vegetation coverage and management practice on soil nitrogen loss by erosion in a hilly region of the Loess Plateau in China. Acta Bot. Sin. 45, 1195-1203.

von Arx, G., Dietz, H., 2006. Growth rings in the roots of temperate forbs are robust annual markers. Plant Biol. 8, 224-233.

von Arx, G., Edwards, P.J., Dietz, H., 2006. Evidence for life history changes in high-altitude populations of three perennial forbs. Ecology 87, 665-674.

von Arx, G., Archer, S.R., Hughes, M.K., 2012. Long-term functional plasticity in plant hydraulic architecture in response to supplemental moisture. Ann. Bot. 109, 1091-1100.

Zhao, Y.F., Zou, X.Q., Zhang, J.X., Cao, L.G., Xu, X.W.H., Zhang, K.X., Chen, Y.Y., 2014. Spatio-temporal variation of reference evapotranspiration and aridity index in the Loess Plateau Region of China, during 1961-2012. Quat. Int. 349, 196-206. 